\title{
The prevalence of detrusor overactivity amongst patients with symptoms of overactive bladder: a retrospective cohort study. Comment
}

\author{
Fulya Dökmeci • Şerife Esra Çetinkaya
}

Published online: 10 April 2013

(C) The International Urogynecological Association 2013

\section{Dear Editor,}

We read with interest the retrospective study by Diamond et al. [1], which aimed to determine the proportion of detrusor overactivity (DO) among patients with overactive bladder (OAB) symptoms included with the authors' suggested criteria. The starting point of these exclusion criteria show some similarities to our previously presented study in which we developed a standardized workup to investigate the urodynamic characteristics of the pure OAB cases [2]. However, the present study has some discrepancy and inadequacy regarding its method, results, and discussion.

First, the authors excluded the patients with prolapse at or beyond the hymen (which means there were still patients with stage 2 prolapse), or with elevated post-void residual (PVR) $>100 \mathrm{ml}$, or those who did not have urodynamics. In our opinion, without excluding the patients with stage 2 prolapse, urinary tract infection or patients who are on medications that may interfere with PVR, it would be hard to comment on the etiopathogenesis of $\mathrm{OAB}$, as the authors tried to do.

The urodynamic testing methods could not be understood clearly (single or multichannel) and the results show inconsistency. Among 93 patients, urodynamic data were reported as DO in 11, and normal in 21 patients. Additional diagnoses were stress incontinence $20.4 \%(n \approx 19)$ and interstitial cystitis $2.1 \%(n \approx 2)$, for which it was unclear whether or not they were urodynamic diagnosis as well. The study fails to report the urodynamic results of the remaining 40 patients.

A reply to this comment is available at doi 10.1007/s00192-013-2086-y

F. Dökmeci $(\bowtie) \cdot$ Ş. E. Çetinkaya

Department of Obstetrics and Gynecology,

Ankara University School of Medicine, Ankara, Turkey

e-mail: fdokmeci@gmail.com
As a conclusion, the authors convey their feeling that it is mandatory to perform assessment for prolapse, incomplete emptying, and urogenital atrophy before initiating an anticholinergic medication. Although we totally agree with this opinion, if the authors derived this feeling through their study, it is inadmissible as the patients with PVR $>100 \mathrm{ml}$ $(7 \%)$, have already been excluded at the beginning and then incomplete bladder emptying was re-defined as "PVR 50$100 \mathrm{cc} "(26.9 \%)$ and reported to be significantly comparable to the rates of the study by Digesu et al. (PVR $>100 \mathrm{ml}$; $8.1 \%$ ) [3]. Hence, the comparison they made of " $26.9 \%$ vs $8.1 \%$ " is a good example of misinterpretation of the results. Additionally, while there were 58 postmenopausal women with only 3 using local and 6 using HRT/OCP, they reported 25 patients with urogenital atrophy whose diagnostic criteria and relation to DO or other parameters have not been mentioned.

It is hard to comprehend the design path of this study from the methodological starting point towards the discussion, as all the aforementioned points indicate the overall incoherency.

\section{References}

1. Diamond P, Hassonah S, Alarab M, Lovatsis D, Drutz HP (2012) The prevalence of detrusor overactivity amongst patients with symptoms of overactive bladder: a retrospective cohort study. Int Urogynecol J 23:1577-1580. doi:10.1007/s00192012-1781-4

2. Dokmeci F, Cetinkaya SE, Yuce T, Gok H (2010) Urodynamic and clinical perspectives of overactive bladder in women. ICS/IUGA 2010 Online Abstracts. http://www.icsoffice.org/Abstracts/Publish/ 105/000362.pdf.

3. Digesu GA, Khullar V, Cardozo L, Salvatore S (2003) Overactive bladder symptoms: do we need urodynamics? Neurourol Urodyn 22:105-108 